\title{
Experimental study of pine forest fuel layer ignition by the steel heated particle
}

\author{
Nikolay V. Baranovskiy, Arkadiy V. Zakharevich and Diana S. Osotova \\ National Research Tomsk Polytechnic University, Institute of Power Engineering, 634050 Tomsk, \\ Russia
}

\begin{abstract}
Experimental research results of ignition processes of typical and widespread forest fuel (pine needles) by single heated up to high temperatures metal particles of the cylindrical form are presented. Ignition delays for particles of the various sizes and initial temperatures are resulted. Ignition conditions are established and a number of features of the investigated process mechanism are marked.
\end{abstract}

\section{Introduction}

It is known, that single heated up to high temperatures metal particles can be sources of ignition of the various condensed substances [1,2] and liquid fuels [3,4]. The theoretical consequences presented in [1-4] well prove to be true results of experimental researches of ignition of propellants [5] and liquid fuels $[6,7]$ by the single heated up to high temperatures particles. It is theoretically proved possibility of ignition of forest fuel by local sources of heating [8-10]. There are no the experimental data that confirming this conclusions till now.

The purpose of the present research is experimental studying of the basic laws and ignition conditions of typical, widespread forest fuel (pine needles) by the single heated up to high temperatures steel particles.

\section{Materials and methods}

Experiments were spent on installation (Fig. 1) and by a technique [5,6] with heated particles of metals in the form of cylinders of two various sizes: diameter $\mathrm{d}=6 \mathrm{~mm}$; height $\mathrm{h}=13 \mathrm{~mm}$; weight $\mathrm{m}=2,5 \mathrm{~g}$; $\mathrm{d}=8 \mathrm{~mm} ; \mathrm{h}=17 \mathrm{~mm} ; \mathrm{m}=6,2 \mathrm{~g}$. It is established, that at influence on forest fuel layer particles in height less than $13 \mathrm{~mm}$ of ignition did not occur.

Forest fuel layer from pine needles litter is object of research. The material for researches has been collected in the Timiryazevskiy forest area of Timiryazevskiy forestry of Tomsk region by the autumn of 2011. Forest fuel samples were formed in fire-resistant cuvette by means of chaotic packing of needles by uniform layer (packing density corresponded to one in the Timiryazevskiy forest area; volume fraction of dry organic substance in layer made nearby 0.06 [11]). Experiments are spent with needles grown brown, partially decayed, preliminary dried up [12]. The sizes of separate needles made

This is an Open Access article distributed under the terms of the Creative Commons Attribution License 4.0, which permits unrestricted use, distribution, and reproduction in any medium, provided the original work is properly cited. 


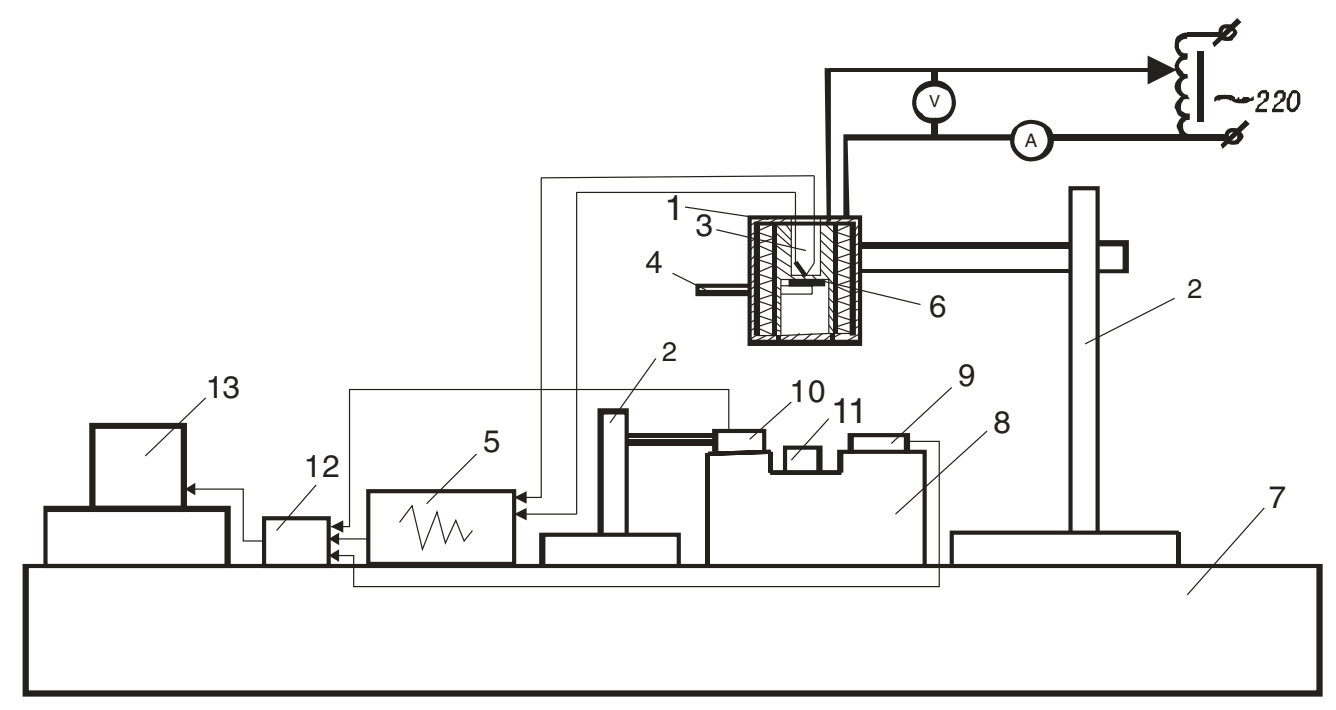

Figure 1. Scheme of experimental installation: 1-heating device, 2-support, 3-hromel-alumel thermocouple, 4ceramic core, 5-control unit of temperature, 6-metal particle, 7-worker surface of experimental installation, 8-fireresistant platform, 9-receiver of radiation and the registrar of flame, 10-radiator, 11-vertical glass cylindrical vessel, 12-analogue-digital converter, 13-personal computer of IBM PC type.

$7-8 \mathrm{sm}$ in longitudinal and $0.7-1.2 \mathrm{~mm}$ in cross-section direction. Drying of forest fuel was spent in drying cabinet within several hours. Removal of moisture from needles proceeded to condition of its full drying corresponding to conditions of catastrophic fire danger [13].

Results of statistical processing of experimental data with confidential intervals with probability belief $\mathrm{P}=0.95$ [14] were defined. Normal distribution of the measured size (ignition delay) was supposed. It was spent not less than five experiences with an identical particle at constant initial temperature.

\section{Results and discussion}

Characteristic shots of video shooting of forest fuel ignition by the heated up to high temperatures particle are presented on Fig. 2. Following laws of process are established. Thermal decomposition of material with release of gaseous products of pyrolysis begins after the short period of inert warming up of forest fuel layer. Forest fuel decays practically completely in surface layer with small coke residue which drops out on substrate. There is a filtration of gaseous products of pyrolysis in porous forest fuel environment to heated surface of layer and their mixing with an oxidizer, heating of gas mix with the subsequent ignition. Then the flame appears on all perimeter of a particle.

Ignition delay dependences on particle initial temperature are presented on Fig. 3. For each particle the bottom limit of ignition on temperature is defined. Confidential intervals are resulted in Table 1. High enough values of mean-square deviations of results of measurements $t_{i g n}$ from average values are caused, obviously, stochastic character of distribution of the separate single needles in surface forest fuel layer which directly heats up by the "hot" particle. The distance between separate needles on border of contact "forest fuel-particle" in the spent experiments was not fixed (as well as in real forest fuel to constants. Therefore in separately taken experience each particle could heat up simultaneously from 3 to 7 needles. Accordingly, for these reasons in single experiment and heat exchange conditions differed between a source of heating and forest fuel. So, for example, at high porosity of surface forest fuel 
Thermophysical Basis of Energy Technologies

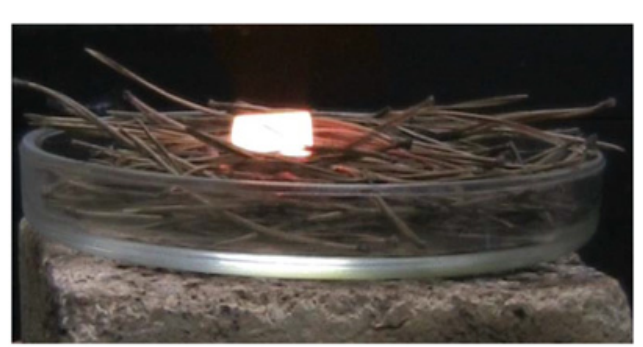

a)

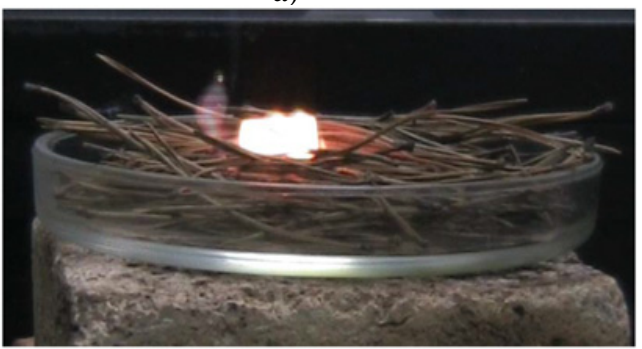

c)

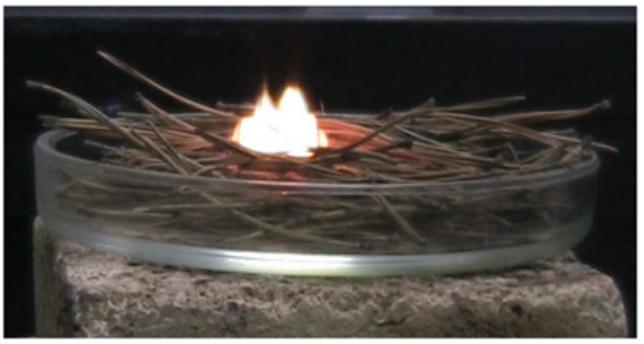

e)

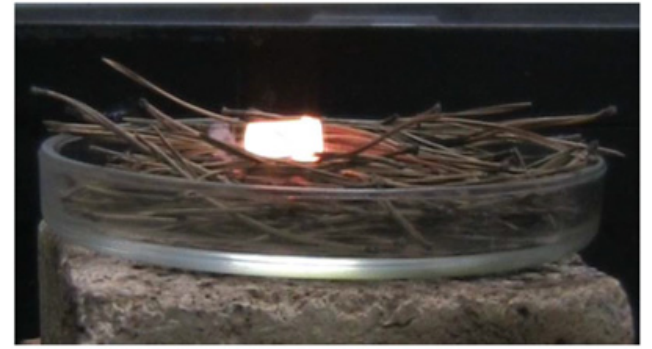

b)

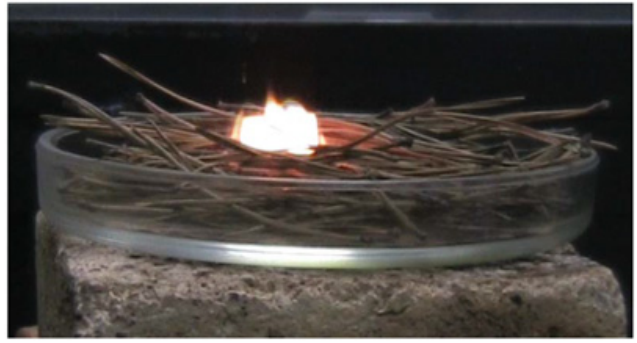

d)

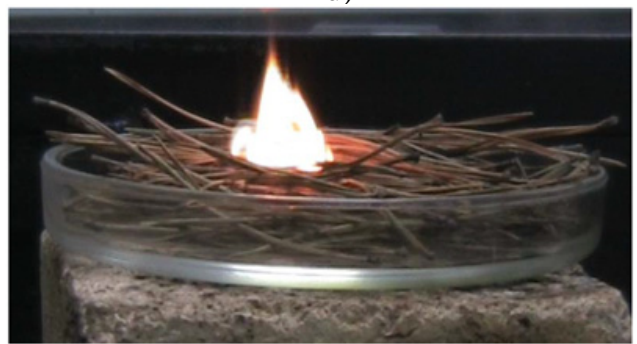

f)

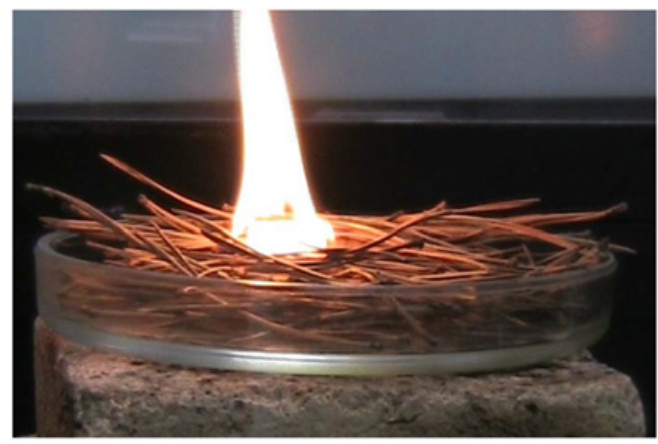

g)

Figure 2. Characteristic shots of video shooting of forest fuel ignition process by heated up to high temperatures particle during the various moments of time: $\mathrm{t}=0,08 \mathrm{~s}$ - inert warming up of forest fuel layer; $\mathrm{t}=0,12 \mathrm{~s}-\mathrm{blown}$ of gaseous products of pyrolysis; $t=0,20 \mathrm{~s}$ - flame occurrence (ignition of forest fuel); $t=0,24 \mathrm{~s}$ - flame occurrence on particle perimeter; $\mathrm{t}=0,32 \mathrm{~s}$ - flame association over particle; $\mathrm{t}=0,52 \mathrm{~s}-$ burning of forest fuel layer in a particle vicinity; $\mathrm{t}=1,08 \mathrm{~s}-$ flame spreading on forest fuel layer.

layer (small number of needles heated up by particle) the material got warm essentially more slowly in comparison with a variant of low porosity of needles (a lot of separate needles which contacted with the "hot" particle). In appropriate way at change of conditions and ignition delay of heated forest fuel 


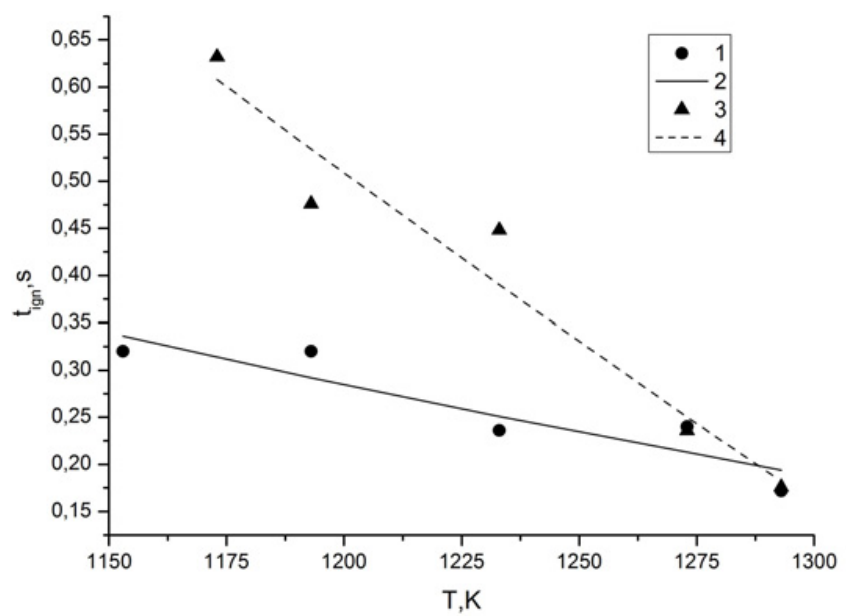

Figure 3. Dependences of forest fuel ignition delay on particle initial temperature: 1,2 - average values and approximating line (particle $\mathrm{d}=8 \mathrm{~mm} ; \mathrm{h}=17 \mathrm{~mm} ; \mathrm{m}=6,2 \mathrm{~g}$ ); 3,4 - average values and approximating line (particle $\mathrm{d}=6 \mathrm{~mm} ; \mathrm{h}=13 \mathrm{~mm} ; \mathrm{m}=2,5 \mathrm{~g}$ ).

Table 1. Confidential intervals of forest fuel ignition delay.

\begin{tabular}{|c|c|c|}
\hline $\begin{array}{c}\text { Initial temperature } \\
\text { of heated particle } \\
\mathrm{T}, \mathrm{K}\end{array}$ & $\begin{array}{c}\text { Confidential } \\
\text { interval, s (particle } \\
\mathrm{d}=8 \mathrm{~mm} ; \\
\mathrm{h}=17 \mathrm{~mm})\end{array}$ & $\begin{array}{c}\text { Confidential } \\
\text { interval, s (particle } \\
\mathrm{d}=6 \mathrm{~mm} ; \\
\mathrm{h}=13 \mathrm{~mm})\end{array}$ \\
\hline 1153 & $\pm 0,061$ & \\
\hline 1173 & & $\pm 0,171$ \\
\hline 1193 & $\pm 0,093$ & $\pm 0,115$ \\
\hline 1233 & $\pm 0,09$ & $\pm 0,041$ \\
\hline 1273 & $\pm 0,137$ & $\pm 0,065$ \\
\hline 1293 & $\pm 0,022$ & $\pm 0,057$ \\
\hline
\end{tabular}

varied from experience to experience because the considerable part of energy of particle was spent for heating of air filling porous structure of forest fuel.

The analysis of dependences shows on Fig. 3 resulted that $t_{i g n}$ does not depend on the sizes of a source of ignition at achievement of initial temperature of particle about $1300 \mathrm{~K}$. Dependence of ignition delay on initial temperature can be approximated by the straight line. It is necessary to notice, that there is a complex interconnected diffusive and convective processes both in porous structure of a material, and over it at ignition of forest fuel. It leads to that the kind of dependence of ignition delay of forest fuel essentially differs from curves, characteristic, for example, for fuel compositions [1,2]. So, in particular, high porosity of needles leads to that the considerable part of thermal energy accumulated in a particle of metal, is radiated into porous space filled with air. Thus warming up of forest fuel layers located on some distance from an interface of environments does not stimulate fast gasification of surface needles layer.

Analysis of the ignition mechanism of pine needles by the heated up to high temperatures particle is carried. It is necessary to notice, that if the characteristic size of porous structure of forest fuel was more the than maximum characteristic size of heated particles, last passed through all layer of needles without forest fuel ignition. Accordingly, it began possible to draw a conclusion on the limiting sizes of "hot" particles at which conditions of ignition of typical forest fuel (pine needles) are satisfied. It is important that the temperature and moisture content of all forest fuel were supported by constants. The 
temperature and moisture content on a thickness of layer essentially change in real pine needles litter. Therefore in the real practice ignition of forest fuel by heated particle of the metal which has got into a layer of needles on some depth is represented improbable.

The executed experiments also have shown high stability of forest fuel layer (with very high (more than 0,9 ) porosity) ignition by the single "hot" particle. The typical visible record (Fig. 2) well illustrates dynamics of investigated process. Occurrence of local microtorch at $t=0,2$ seconds on small part of surface of the sample comes to the end through 0,88 seconds with flame formation on all contour of a source of heating. Good heated separate needles, adjoining a surface of a steel particle, are ignited, as well as it was possible to predict.

\section{Conclusion}

The spent experimental researches of forest fuel ignition by the heated up to high temperatures steel particles in the range of temperatures typical for natural fires and real fire-dangerous sources, have confirmed possibility of forest fuel ignition proved earlier theoretically with single "hot" particles. Dependences of ignition delay on initial temperature of particle are established. Ignition condition limited by the initial temperatures of particles and their sizes are marked which realization of such mechanism of ignition of typical forest fuel (pine needles litter) is possible. The mechanism of occurrence of ignition is identified at influence by the single heated up to high temperatures particles of metals. Obtained results can be useful for development of advanced deterministic mathematical models applying to forest fire danger prediction [15-21].

\section{References}

[1] G.V. Kuznetsov, G.Ya. Mamontov, G.V. Taratushkina, Khimicheskaya fizika, 23, 67 (2004) (In Russian)

[2] G.V. Kuznetsov, G.Ya. Mamontov, G.V. Taratushkina, Combustion, Explosion and Shock Waves, 40, 70 (2004)

[3] G.V. Kuznetsov, P.A. Strizhak, Journal of Engineering Thermophysics, 17, 244 (2008)

[4] G.V. Kuznetsov, P.A. Strizhak, Fire safety, 4, 72 (2008) (In Russian)

[5] A.V. Zaharevich, V.T. Kuznetsov, G.V. Kuznetsov, V.I. Maksimov, Combustion, Explosion and Shock Waves, 44, 543 (2008)

[6] G.V. Kuznetsov, A.V. Zaharevich, V.I. Maksimov, Pozharovzryvobezopasnost, 17, 28 (2008) (In Russian)

[7] A.V. Zaharevich, G.V. Kuznetsov, V.I. Maksimov, Pozharovzryvobezopasnost, 17, 39 (2008) (In Russian)

[8] G.V. Kuznetsov, N.V. Baranovskiy, Khimicheskaya fizika I mezoskopiya, 13, 173 (2011) (In Russian)

[9] N.V. Baranovskiy, Matematicheskoe modelirovanie naibolee veroyatnikh scenariev $i$ usloviy vozniknoveniya lesnikh pozharov. Diss. ... Cand. fiz.-mat. nauk. (2007) (In Russian)

[10] G.V. Kuznetsov. N.V. Baranovskiy, Butlerovskie soobshcheniya, 22, 30 (2010) (In Russian)

[11] A.M. Grishin, V.T. Kuznetsov, A. Skorik, Combustion, Explosion and Shock Waves, 38, 24 (2002)

[12] A.M. Grishin, N.V. Baranovskiy, Journal of Engineering Physics and Thermophysics, 76, 166 (2003)

[13] M.D. Flannigan, B.J. Stocks, B.M. Wotton, Science of the Total Environment, 262, 221 (2000)

[14] V.E. Gmurman, Teoriya veroyatnosti I matematicheskaya statistika. (2003) (In Russian)

[15] N.V. Baranovskiy, Sibirskiy ecologicheskiy zhurnal, 6, 835 (2004) (In Russian)

[16] N.V. Baranovskiy, Ecologia i promyshlennost Rossii, 9, 59 (2008) (In Russian)

[17] G.V. Kuznetsov, N.V. Baranovskiy, EPJ Web of Conferences.76, (01028), 1 (2014) 
[18] N.V. Baranovskiy, M.V. Zharikova, Lecture Notes in Geoinformation and Cartography - LNG\&C. Thematic Cartography for the Society. 13 (2014)

[19] N.V. Baranovskiy, E.P. Yankovich, Proceedings of 5th International Conference on Cartography and GIS (Riviera, Bulgaria, 15 - 20 june 2014), 2, 756 (2014)

[20] e.P. Yankovich, N.V. Baranovskiy, $14^{\text {th }}$ International Multidisciplinary Scientific Geoconference SGEM - 2014. GeoConference on Informatics, Geoinformatics and Remote Sensing, 1, 607 (2014) (DOI: 10.5593/sgem2014B21)

[21] G.V. Kuznetsov, N.V. Baranovskiy, Proceedings of SPIE, 8890, paper 889011 (2013) doi:10.1117/12.2033929 